\title{
ANTIBIOGRAM OF SALMONELLA SPP ISOLATES IN KATHMANDU, NEPAL
}

Damodar Gajurel ${ }^{1}$, Rabi Prakash Sharma ${ }^{1}$, Krishna Dhungana ${ }^{1}$, Samir Neupane ${ }^{1}$, Kamal Lamsal ${ }^{1}$, Prasant Karki ${ }^{1}$, Sudikshya Acharya ${ }^{1}$

\section{ABSTRACT}

\section{INTRODUCTION:}

Drug resistant Salmonella spp. is endemic in several Asian countries. Nalidixic acid-resistant Salmonella enterica serovar Typhi and Salmonella enterica serovar Paratyphi A show reduced susceptibility to fluoroquinolones and have resulted in a rise in treatment failures. Over the past few decades, nalidixic acid-resistant Salmonella spp have emerged in Nepal as well.

\section{MATERIAL \& METHODS:}

This is a retrospective study that aims to provide a more recent antibiogram of $S$. Typhi and $S$. Paratyphi A isolates in Kathmandu. Between Poush, 2071 and Ashwin, 2072 (December 16, 2014 to October 17, 2015), 186 culture positive cases of enteric fever were diagnosed at the Civil Service Hospital. Upon isolation of $S$. Typhi or S. Paratyphi A, antimicrobial susceptibility testing was performed with amoxicillin, azithromycin, ceftriaxone, chloramphenicol, ciprofloxacin, cotrimoxazole, nalidixic acid, ofloxacin and tetracyciline.

\section{RESULTS:}

This study shows a much higher frequency of nalidixic acid-resistance in Kathmandu than previously reported; 95.7\% in Salmonella enterica serovar Paratyphi A and 86.5\% in Salmonella enterica serovar Typhi.The rates of ciprofloxacin- and ofloxacin-resistance were over $50 \%$ in both serovar.

\section{CONCLUSION:}

In Nepal, it is necessary to reevaluate the use of fluoroquinolone therapy and introduce feasible alternatives so as to curb treatment failures.

KEY WORDS: $S$. Typhi, $S$. Paratyphi A, nalidixic-resistance, fluoroquinolones

1. Department of Medicine, Civil Service Hospital, Minbhawan, Kathmandu, Nepal

\author{
For correspondence \\ Dr. Rabi Prakash Sharma \\ Department of Medicine, \\ Civil Service Hospital, \\ Minbhawan, \\ Kathmandu, Nepal \\ Email: rabiprakash2001@yahoo.com
}




\section{INTRODUCTION}

Enteric fever is endemic and a major cause of febrile illness in Nepal. The disease is mainly transmitted through contaminated food and water. It thrives in environments of poor sanitation and inadequate supply of clean water ${ }^{1}$.In addition to Salmonella enterica serovar Typhi (S. Typhi), Salmonella enterica serovar Paratyphi-A ( $S$. Paratyphi) has emerged as a major causative organism in the past decade ${ }^{2-4}$. The incidence of paratyphoid cases has been reported to be higher than the incidence of typhoid cases in Kathmandu ${ }^{4}$.

Nalidixic acid-resistant strains of $S$. Typhi have been reported since the early 1990's in Asia. These strains have shown reduced susceptibility to ciprofloxacin in various countries, for instance, Vietnam, Japan and Tajikistan ${ }^{5-7}$. Moreover, it has been suggested that such strains are endemic in neighbouring countries, India and Pakistan ${ }^{8}$. Nalidixic acid-resistant $S$. Paratyphi A isolates in India have also shown reduced susceptibility to ciprofloxacin ${ }^{9}$. Recent evidence shows a high rate of nalidixic acid-resistant strains of $S$. Typhi and $S$. Paratyphi A in Nepal as well ${ }^{10,11}$.In Kathmandu, the rate of nalidixic acid-resistance in $S$. Paratyphi A strains has been reported to be higher than in $S$. Typhi strains ${ }^{11}$.

Furthermore, a 2006 study conducted in Kathmandu revealed that patients infected with either serovar presented with indistinguishable clinical syndromes, dismissing the assumption that $S$. Paratyphi A causes a milder disease ${ }^{12}$.With the increasing incidence of paratyphoid cases in Nepal and the higher prevalence of drug resistance among these cases, an increase in the rate of treatment failures may be a concern ${ }^{11}$.In Nepal, $S$. Typhi and $S$. Paratyphi A isolates have been susceptible to fluoroquinolones in the past, however, this is no longer true $\mathrm{e}^{12,13}$. This retrospective study aims to provide a more recent antibiogram of $S$. Typhi and $S$. Paratyphi A isolates in Kathmandu.

\section{MATERIAL \& METHODS}

The Civil Service Hospital in Kathmandu provides affordable medical services to the inhabitants of Kathmandu Valley and the surrounding area. The microbiology laboratory at this hospital is equipped with culture facilities for the diagnosis of bacterial infections. Between Poush, 2071 and Ashwin, 2072 (December 16, 2014 to October 17, 2015), 186 culture positive cases of enteric fever were diagnosed between at this location. The BACTEC ${ }^{\text {TM }}$ FX blood culture system was initially used to detect microbial growth. Positive samples were then incubated in MacConkey agar and blood agar for 24 hours. Upon isolation of $S$. Typhi or $S$. Paratyphi A, antimicrobial susceptibility testing (AST) was performed using the Kirby-Bauer disk diffusion method. All $S$. Typhi and $S$. Paratyphi A isolates were tested for susceptibility with amoxicillin, azithromycin, ceftriaxone, chloramphenicol, ciprofloxacin, cotrimoxazole, nalidixic acid, ofloxacin and tetracyciline.

Medical data were obtained from MiDAS, an electronic medical records software used by the laboratories at the Civil Service Hospital. Excel 2013 for Windows and IBM SPSS Statistics 20 for Windows were used for data analysis.

\section{RESULTS}

Of the 182 patients that presented with enteric fever, 88 were infected with $S$. Typhi (48.4\%), and 94 were infected with $S$. Paratyphi A (51.6\%). Two $S$. Typhi and two $S$. Paratyphi A cases were excluded from the study because the complete antibiogram for these cases were not available. A higher rate of nalidixic acid resistance was seen in $S$. Paratyphi A isolates than in $S$. Typhi isolates $(95.7 \%$ vs. $86.5 \%)$. The rates of ciprofloxacin- and ofloxacin-resistance were similar in both serovars. Amoxicillin-resistance was more common in $S$. Paratyphi A isolates when compared to $S$. Typhi isolates $(68 \%$ vs. $24.7 \%$ ). All $S$. Typhi isolates were susceptible to ceftriaxone, chloramphenicol and tetracyciline while all $S$. Paratyphi A isolates were susceptible to ceftriaxone, chloramphenicol and cotrimoxazole. Susceptibility to chloramphenicol and cotrimoxazole has increased from rates seen in $2002^{12}$. Antibiogram of S. Typhi and S. Paratyphi A isolates are shown in Table 1 and Table 2 respectively.

\begin{tabular}{|l|l|l|l|}
\hline \multirow{2}{*}{ Antibiotic } & \multicolumn{3}{|l|}{ Antibiogram of S. Typhi isolates } \\
\cline { 2 - 4 } & $\begin{array}{l}\text { Susceptible } \\
\mathrm{n}(\%)\end{array}$ & $\begin{array}{l}\text { Resistant } \\
\mathrm{n}(\%)\end{array}$ & $\begin{array}{l}\text { Intermediate } \\
\mathrm{n}(\%)\end{array}$ \\
\hline Amoxicillin & $53(59.6)$ & $22(24.7)$ & $14(15.7)$ \\
\hline Azithromycin & $68(76.4)$ & $3(3.4)$ & $18(20.2)$ \\
\hline Ceftriaxone & $89(100)$ & $0(0)$ & $0(0)$ \\
\hline Chloramphenicol & $89(100)$ & $0(0)$ & $0(0)$ \\
\hline Ciprofloxacin & $13(14.6)$ & $49(55.1)$ & $27(30.0)$ \\
\hline Cotrimoxazole & $87(97.8)$ & $2(2.2)$ & 0 \\
\hline Nalidixic Acid & $11(12.4)$ & $77(86.5)$ & $1(1.1)$ \\
\hline Ofloxacin & $13(14.6)$ & $48(53.9)$ & $28(31.5)$ \\
\hline Tetracyciline & $89(100)$ & $0(0)$ & $0(0)$ \\
\hline
\end{tabular}

Table 1. Antibiogram of $S$. Typhi isolates. 


\begin{tabular}{|l|l|l|l|}
\hline \multirow{2}{*}{ Antibiotic } & \multicolumn{3}{|c|}{ Antibiogram of $S$ Paratyphi A isolates } \\
\cline { 2 - 4 } & $\begin{array}{l}\text { Susceptible } \\
\mathrm{n}(\%)\end{array}$ & $\begin{array}{l}\text { Resistant } \\
\mathrm{n}(\%)\end{array}$ & $\begin{array}{l}\text { Intermediate } \\
\mathrm{n}(\%)\end{array}$ \\
\hline Amoxicillin & $23(24.5)$ & $64(68.0)$ & $7(7.5)$ \\
\hline Azithromycin & $57(60.6)$ & $7(7.5)$ & $30(31.9)$ \\
\hline Ceftriaxone & $94(100)$ & $0(0)$ & $0(0)$ \\
\hline Chloramphenicol & $94(100)$ & $0(0)$ & $0(0)$ \\
\hline Ciprofloxacin & $7(7.5)$ & $49(52.1)$ & $38(40.4)$ \\
\hline Cotrimoxazole & $94(100)$ & $0(0)$ & $0(0)$ \\
\hline Nalidixic Acid & $4(4.3)$ & $90(95.7)$ & $0(0)$ \\
\hline Ofloxacin & $6(6.4)$ & $49(52.1)$ & $39(41.5)$ \\
\hline Tetracyciline & $93(98.9)$ & $1(1.1)$ & $0(0)$ \\
\hline
\end{tabular}

Table 2. Antibiogram of S. Paratyphi A isolates.

\section{DISCUSSION}

The ability to achieve high concentrations in macrophages, bowel, bile and the urinary tract coupled with easy administration (i.e. oral) has made fluoroquinolones the drugs of choice for the treatment of enteric fever'. Nalidixic acidresistant Salmonella spp isolates show a decreased clinical response to fluoroquinolones ${ }^{14}$. There is increasing evidence that while AST may demonstrate the minimum inhibitory concentration of Salmonella spp isolates to fall within the susceptibility range, this result may not be indicative of clinical response $\mathrm{e}^{14}$. Hence, it has been recommended that nalidixic acid-resistance be used as an indicator for clinical response to fluoroquinolones, and that short course-short fluoroquinolone therapy be avoided for the treatment of enteric fever caused by nalidixic acid-resistant isolates ${ }^{15,16}$.

This study found a higher rate of nalidixic acid-resistance in Salmonella spp isolates than previously reported in Kathmandu ${ }^{11,12}$. Consistent with previous evidence, S. Paratyphi A was more likely to be nalidixic acid-resistant when compared with $\mathrm{S}$. Typhi ${ }^{11,12}$. While nalidixic acidresistance should be used as an indicator for the prescription of fluoroquinolones, AST is not widely available in Nepal, and ciprofloxacin and ofloxacin are widely used for the treatment of enteric fever ${ }^{11,12}$. Moreover, antimicrobials are available from pharmacies without a prescription. These factors may be involved in the spread of drug-resistant Salmonella spp isolates in Kathmandu. Among other methods to control enteric fever, vaccination has been widely used worldwide. Immunization against $S$. Typhi does not provide effective cross-protection against $S$. Paratyphi A, and there are no licenced vaccines against $S$. Paratyphi $\mathrm{A}^{17}$.Although annual vaccination of school children in Thailand against $S$. Typhi has been effective in decreasing the incidence of overall typhoid fever, a decrease in the incidence of $S$. Paratyphi A was not reported $^{18}$. With the high prevalence of $S$. Paratyphi A in the community, it is not clear whether immunization would be an effective option in Kathmandu. Further studies are required to evaluate the feasibility of mass vaccination against enteric fever in Nepal.

Along with an improvement in a consistent supply of clean water and sanitation, enteric fever-specific education across various population such as school children, food handlers, pharmacists, and pharmacy attendants would be beneficial in the control of enteric fever in Nepal. Particularly, education for pharmacy attendants regarding the risks of antimicrobial sales without prescriptions could be helpful in reducing the indiscriminate use of these drugs.

\section{CONCLUSION}

The limited number of health facilities that offer AST; the widespread and indiscriminate use of fluoroquinolones; and inadequate supply of clean water and poor sanitation in crowded urban settings in Kathmandu is a major concern with respect to the spread of drug resistant strains of Salmonella spp. With the spread of drug resistant strains, treatment failure has been reported from around world. The rate of nalidixic acid-resistant S. Typhi and S. Paratyphi A is alarmingly high in Kathmandu, much higher than previously reported. Moreover, more than $50 \%$ of both Salmonella serovars showed resistance to ciprofloxacin and ofloxacin. The emergence of untreatable typhoid and paratyphoid fever may soon be a reality in Kathmandu.

\section{ACKNOWLEDGEMENT}

We would like to thank the staff of the microbiology laboratory at the Civil Service Hospital for their help in collecting data.

\section{REFERENCES}

1 Parry CM, Hien TT, Dougan G, White NJ, Farrar JJ. Typhoid fever. NEngl JMed. 2002;347:1770-1782.

2 Woods CW, Murdoch DR, Zimmerman MD, Glover WA, Basnyat $B$, Wolf L, Belbase RH, Reller LB. Emergence of Salmonella enterica serotype Paratyphi A as a major cause of enteric fever in Kathmandu, Nepal. Trans $R$ Soc Trop Med Hyg. 2006 Nov;100(11):1063-7.

3 Acharya D, Bhatta DR, Malla S, Dumre SP, Adhikari N, Kandel BP.Salmonella enterica serovar Paratyphi A: an emerging cause offebrile illness in Nepal. Nepal Med Coll J. 2011 Jun;13(2):6973. 
4 Pokharel P, Rai SK, Karki G, Katuwal A, Vitrakoti R, Shrestha SK. Study of enteric fever and antibiogram of Salmonella isolates at a teaching hospital in Kathmandu Valley. Nepal Med Coll J. 2009 Sep;11(3):176-8.

5 Wain J, Hoa NT, Chinh NT, Vinh H, Everett MJ, Diep TS, Day NP, Solomon T, White NJ, Piddock LJ, Parry CM. Quinoloneresistant Salmonella typhi in Viet Nam: molecular basis of resistance and clinical response to treatment. Clin Infect Dis. 1997 Dec;25(6):1404-10.

6 Murdoch DA, Banatvaia N, Bone A, Shoismatulloev BI, Ward LR, Threlfall EJ.Epidemic ciprofloxacin-resistant Salmonella typhi in Tajikistan. Lancet. 1998 Jan 31;351(9099):33-9.

7 Hirose K, Tamura K, Sagara H, Watanabe H.Antibiotic susceptibilities of Salmonella enterica serovar Typhi and $S$. enterica serovar Paratyphi A isolated from patients in Japan. Antimicrob Agents Chemother. 2001 Mar;45(3):956-8.

8 Threlfall EJ, Ward LR, Skinner JA, Smith HR, Lacey S. Ciprofloxacin-resistant Salmonella typhi and treatment failure. Lancet. 1999 May 8;353(9164):1590-1.

9 Joshi S, Amarnath SK. Fluoroquinolone resistance in Salmonella typhi and S. paratyphi A in Bangalore, India. Trans $R$ Soc Trop Med Hyg. 2007 Mar; 101(3):308-10.

10 Lewis MD, Serichantalergs O, Pitarangsi C, Chuanak N, Mason $C J$, Regmi LR, Pandey P, Laskar R, Shrestha CD, Malla S. Typhoid fever: a massive, single-point source, multidrugresistant outbreak in Nepal. Clin Infect Dis. 2005 Feb 15;40(4):554-61.

11 Murdoch DR, Woods CW, Zimmerman MD, Dull PM, Belbase RH, Keenan AJ, Scott RM, Basnyat B, Archibald LK, Reller LB.The etiology of febrile illness in adults presenting to Patan hospital in Kathmandu, Nepal. Am J Trop Med Hyg. 2004 Jun;70(6):670-5.
12 Maskey AP, Day JN, Phung QT, Thwaites GE, Campbell JI, Zimmerman M, Farrar JJ, Basnyat B. Salmonella enterica serovar Paratyphi $A$ and S. enterica serovar Typhi cause indistinguishable clinical syndromes in Kathmandu, Nepal. Clin Infect Dis. 2006 May 1;42(9):1247-53.

13 Malla S, Kansakar P, Serichantalergs O, Rahman M, Basnet S. Epidemiology of typhoid and paratyphoid fever in Kathmandu: two years study and trends of antimicrobial resistance. JNMA J Nepal Med Assoc. 2005 Jan-Mar;44(157):18-22.

14 Aarestrup FM, Wiuff C, Mølbak K, Threlfall EJ. Is it time to change fluoroquinolone breakpoints for Salmonella spp.? Antimicrob Agents Chemother. 2003 Feb;47(2):827-9.

15 Hakanen A, Kotilainen P, Jalava J, Siitonen A, Huovinen P. Detection of decreased fluoroquinolone susceptibility in Salmonellas and validation of nalidixic acid screening test. $J$ Clin Microbiol. 1999 Nov;37(11):3572-7.

16 Crump JA, Barrett TJ, Nelson JT, Angulo FJ. Reevaluating fluoroquinolone breakpoints for Salmonella enterica serotype Typhi and for non-Typhi salmonellae. Clin Infect Dis. $2003 \mathrm{Jul}$ 1;37(1):75-81.

17 McClelland M, Sanderson KE, Clifton SW, Latreille P, Porwollik $S$, Sabo A, Meyer R, Bieri T, Ozersky P, McLellan M, Harkins CR, Wang $C$, Nguyen C, Berghoff A, Elliott G, Kohlberg S, Strong C, Du F, Carter J, Kremizki C, Layman D, Leonard S, Sun H, Fulton L, Nash W, Miner T, Minx P, Delehaunty K, Fronick C, Magrini V, Nhan M, Warren W, Florea L, Spieth J, Wilson RK. Comparison of genome degradation in Paratyphi $A$ and Typhi, humanrestricted serovars of Salmonella enterica that cause typhoid. Nat Genet. 2004 Dec;36(12):1268-74.

18 Bodhidatta L, Taylor DN, Thisyakorn U, Echeverria P. Control of typhoid fever in Bangkok, Thailand, by annual immunization of schoolchildren with parenteral typhoid vaccine. Rev Infect Dis. 1987 Jul-Aug;9(4):841-5. 